\title{
UNA OBRA INÉDITA DEL PLATERO VALLISOLETANO HIPOLITO BERCIAL DEL VALLE
}

\author{
por Maria del Carmen Heredia Moreno
}

\begin{abstract}
RESUMEN del artículo "Una obra inédita del platero vallisoletano Hipólito Bercial del Valle".
Se estudia en este trabajo una obra desconocida de un platero vallisoletano de finales del siglo XVIII, localizada gracias a documentos extraídos del Archivo de Indias de Sevilla. También se hace una valoración de la trayectoria personal y profesional del citado maestro.
\end{abstract}

This paper offers a study of a previously unknown work by an 18th century Valladolid silversmith, Hipólito Bercial del Valle, found thanks to documents from the Archive of the Indies in Seville. The personal and professional life of this craftsman is also assessed.

Hace unos años tuvimos ocasión de manejar en el Archivo de Indias de Sevilla un interesante conjunto de documentos que trataban sobre las sucesivas tentativas del platero vallisoletano Hipólito Bercial del Valle para obtener el cargo de contraste de corte y que se podían desglosar en dos bloques principales ${ }^{1}$. Por una parte, el recurso interpuesto en el año 1801 por los plateros Gregorio Izquierdo y el propio Hipólito contra la decisión del subdelegado de la Junta de Comercio y Moneda en la ciudad, José Valdés, de admitir a examen a individuos que no cumplían los requisitos de las Ordenanzas de 1771 . Por otra parte, la documentación referida a la solicitud y obtención del ansiado cargo de marcador de corte por parte de Bercial.

El recurso generó una copiosa documentación que incluye un amplio memorial del Colegio de Plateros, un minucioso informe de contestación por parte del subdelegado de Valladolid y el dictamen final de la propia Junta de Comercio. Por su parte, el segundo grupo de documentos comprende todo el dosier generado por la propia solicitud y admisión de Bercial así como el expediente mandado formar en el año 1804 por Manuel Laso, ministro de la Real Junta de Comercio, Moneda y Minas para el examen de ensayador de los Reinos y fiel contraste de la ciudad de Valladolid a Hipólito Bercial del Valle, artífice platero y fiel contraste nombrado, vecino de la propia ciudad. Este expediente engloba, a su vez, tanto la serie de documentos aportados por el aspirante Bercial según los requisitos legales en vigor como el resultado del cuestionario hecho a varios testigos,

1. La documentación procede del Archivo General de Indias. Indiferente General. 1700. 
además del certificado de aprendizaje de ensayador, el acta de examen o el título expedido a favor de Bercial del Valle. En resumen, todo este bloque documental, en su conjunto, contiene sustanciosas noticias biográficas y profesionales sobre el maestro, sobre el Colegio vallisoletano y sobre la Junta de Comercio, además de algunas otras referidas a artífices plateros de distinta procedencia.

Dado el interés de la documentación y la cantidad de datos inéditos que aportaba, decidimos entonces dividir la posible investigación en dos partes. La primera de ellas trataría sobre los intentos de Bercial por conseguir el codiciado puesto de contraste de corte, que por fin logró el día 23 de noviembre del año 1804 , cuyas vicisitudes daban pie para analizar ciertos aspectos del funcionamiento del Colegio y sus relaciones con la Junta. Este tema, bajo el título El platero vallisoletano Hipólito Bercial del Valle y la Junta de Comercia y Moneda de Madrid lo presentamos a las "III Jornadas de Arte Madrileño" celebradas en dicha ciudad en el año $1986^{2}$.

En el segundo estudio, planteado con un criterio de carácter más biográfico, teníamos la intención de recoger los aspectos de la vida privada y profesional de Bercial del Valle y añadirle las escasas noticias publicadas por la bibliografía reciente, además de intentar localizar alguna obra que el artífice cita en su "curriculum". Con todo ello pretendíamos llegar a un mejor conocimiento de este platero que, según la nueva documentación, donde se mencionaban los cargos que desempeñó a lo largo de su vida, las relaciones que tuvo y las instituciones vallisoletanas para las que trabajó, se nos presentaba como una de las personalidades más notables del Arte de la Platería de Valladolid al filo del 1800, pese a las pocas referencias sobre su vida y obra conocidas hasta la fecha ${ }^{3}$.

2. El trabajo se ha publicado en las Actas currespondientes Cinco siglos de Arte en Madrid (XV-XX). Madrid, 1991, págs. 351-360. Posteriormente se publicó el artículo de los Dres. M. HERRÁEZ y J. PANIAGUA: Plateria vallisoletana. Documentación del Archivo General de Indias de Sevilla, "Estudios Humanísticos", n. ${ }^{\circ}$, 1987, págs. $155-164$ que utiliza la misma documentación aunque la analiza desde perspectivas distintas a la nuestra.

3. Las primeras noticias las recogieron E. VALDIVIESO: Catálogo Monumental de la provincia de Valladolid. Antiguo Partido Judicial de Peñafiel, Valladolid, 1975, pág. 197 y PARRADO DEL OLMO, J.: Catálogo Monumental de la provincia de Valladolid. Partido Judicial de La Mota del Marqués, Valladolid, 1976, pág. 182, que dieron a conocer el nombre y la marca de Bercial en un par de obras ejecutadas para iglesias de la provincia, concretamente la lámpara de Pesquera de Duero, obra de 1813, y las Vinajeras de San Pelayo, fechadas en 1804. Poco después C. BRASAS: La platería vallisoletana y su difusión, Valladolid, 1980, págs. 258 y 46 amplió la biografía del artífice aportando ciertos datos de los años 1779 a 1816 referentes a su vinculación con la Academia de la Purísima Concepción y a su gestión en el desempeño de la contrastía. Recientemente M. ÁLVAREZ GARCIA: El Clero de la Diócesis de Valladolid durante la Guerra de la Independencia, Valladolid, 1984, págs. 148-150 ha puesto de manifiesto su intervención para evitar la destrucción de las alhajas del suprimido convento de San Benito de Valladolid en la francesada y, por último, J.J. MARTíN GONZÁLEZ y J. URREA: Catálogo Monumental de la provincia de Valladolid. Tomo XIV, parte $1 .^{a}$. Monumentos religiosos de la ciudad de Valladolid, Valladolid, 1985, pág. 203 hallaron su marca de artífice-H/BERCIAL-en la cruz parroquial de Santiago de Valladolid que ha venido a incrementar de manera modesta el exiguo catálogo de sus obras. También se conocía su marca de contraste de corte -BERCIAL- fecha- estampada en las cruces parroquiales de Camportedondo, obra de Antonio de Ampudia, y de Castronuevo, y en la base de la custodia de la catedral de Avila labrada por Gregorio Izquierdo (Vid. C. BRASAS: Op. cit., págs. 274, 275 y 283), así como en la cruz parroquial de Mota del Marqués (J.M. PARRADO DEL OLMO: Op. cit, pág. 86) y en un jarro del Museo Lázaro Galdiano (J.M. CRUZ VALDOVINOS: Introducción a la colección de platería del Museo Lázaro Galdiano, "Goya", n. os 193-195, año 1986, pág. 38. 
Pero esta segunda investigación se fue demorando por circunstancias diversas $^{4} y$, aunque el trabajo estaba planteado en sus líneas generales, la redacción definitiva había quedado pendiente del reajuste final de ciertos datos. Por ello, cuando tuvimos noticias de la publicación de los Dres. Herráez y Paniagua, decidimos abandonar el proyecto, puesto que muchos de los datos inéditos sobre Bercial aparecían recogidos allís.

Sin embargo, la reciente localización de una obra del artífice y la nueva lectura del artículo citado han vuelto a reavivar nuestro interés por este maestro, por lo que hemos decidido abordar de nuevo su estudio para darla a conocer y para añadir algunas observaciones que, creemos, pueden ayudar a completar el perfil humano y profesional del platero.

La instancia que presenta Bercial en Madrid el día quince de diciembre de 1801 solicitando el cargo de contraste por muerte de don Antonio González Téllez constituye un auténtico "curriculum vitae" donde el maestro da minuciosa cuenta de sus méritos personales y profesionales así como de sus buenas relaciones con miembros muy deståcados de la Academia de la Purísima Concepción, la nobleza local y algunos compañeros de profesión ${ }^{6}$. En cuanto a sus propios trabajos, el platero destaca "entre otras de oro y plata, metales y piedras de su arte, las andas para la imagen de Nuestra Señora de la Valbanera de la parroquial del Salvador que se han merecido la atención de cuantos las han visto por su bella idea y buena disposición". Aquí conviene recordar que Bercial se había bautizado el dieciséis de agosto del año 1759 en esta misma parroquia con la que, sin duda, seguiría manteniendo lazos afectivos o de tipo religioso que, posiblemente, motivarían el encargo en cuestión ${ }^{7}$ y que, a pesar de opiniones recientes que las dan por desaparecidas, las andas de la Virgen presiden todavía hoy el retablo titular de la capilla de Nuestra Señora de la Valbanera de la mencionada iglesia donde recibe culto la imagen. La noticia de su desaparición parece proceder de la lectura apresurada de ciertos documentos publicados hace unos años ${ }^{8}$, pero la

4. Entre otras, la petición y consecución de la foto de la marca de contraste de Bercial, incorporada en el expediente, de la que entonces no existía negativo en el Archivo de Indias, supuso varios meses de demora.

5. M. HERRÁEZ y J. PANIAGUA: Op. cit.

6. Sobre la consecución del cargo de marcador puede consultarse nuestro trabajo antes citado en el texto El platero vallisoletano...

7. El nombre de la parroquia figura en el traslado de la partida de Bautismo que hace el párroco Jacinto Becerril el día 22 de junio de 1804 y que está incorporado en el expediente para el examen de ensayador de Bercial.

8. C. BRASAS: $O p$. cit., pág. $82,206,215,252,253,265,274$ y 289 recoge diversas noticias sobre la parroquia del Salvador y analiza o menciona varias piezas de plata realizadas para la iglesia entre los años 1615 y 1771 por distintos plateros, entre las cuales no figuran ni las andas ni el artífice que nos ocupa. Además Brasas transcribe un inventario de alhajas de la catedral y parroquias vallisoletanas del año 1835 , en el que, en lo referente a la parroquia del Salvador, se dice "una cruz parroquial, seis candelabros, cinco cálices, un juego de sacras y evangelios de plata, seis ramilletes, etc.". En este texto se fundamentan los Dres. HERRÁEZ y PANIAGUA: Op. cit., pág. 162, nota 13 para afirmar la desaparición de las andas, pero hay que tener presente que el "ete" final indica que el inventario no está completo. 
identificación de la obra está fuera de dudas por las coincidencias de lugar, estilo y cronología con los que cita el propio autor en su instancia. Ya los profesores Martín González y Urrea habían hecho alusión a la corona y a la peana de plata de la capilla de la Virgen de Valbanera y habían clasificado ambas piezas correctamente en el siglo XVIII, aunque sin adjudicárselas a ningún artífice concreto ${ }^{9}$. Sin embargo, hoy podemos afirmar que, al menos, las andas fueron hechas por Bercial del Valle antes del quince de diciembre del año 1801. Por todo ello y dado que se trata de uno de los poquísimos trabajos conocidos de este maestro nos ha parecido interesante analizarlas y reproducirlas pese a que su calidad dista mucho de la opinión que la obra mereció a sus contemporáneos según el parecer del artífice.

Las andas (Fig. 1), de plata en su color y de considerable tamaño (102 x 102 cms. de lado de base y $170 \mathrm{cms}$. de altura) tienen planta cuadrada con los ángulos en chaflán donde se insertan cuatro pedestales prismáticos en los que apoyan otros tantos fustes estriados de columnas que soportan, a su vez, figuras de ángeles de madera sobredorada ${ }^{10}$ (Fig. 2). Estas imágenes, de canon esbelto y elegantes actitudes según el gusto neoclásico, pero toscas de detalle, sujetan las cuatro bandas superiores de traza curvilínea avolutada que sirven de culminación al conjunto concebido a modo de baldaquino o templete diáfano con las cuatro caras transparentes. En su interior se alza una peana moldurada de escasa altura, cuya planta repite la de la base del templete y cuya franja interna presenta cenefas de ochos centradas por flores. Los plintos prismáticos se decoran con motivos en "ese" agrupados por parejas y el borde externo del basamento ostenta amplia cenefa de ces vegetalizadas con una cartela con el anagrama de María en el centro del frente anterior (Fig. 3).

En su conjunto, la pieza responde al gusto neoclásico del último tercio del siglo XVIII, particularmente perceptible en la planta, tipo de soportes, figuras y motivos ornamentales. Incluso, si bien en el ritmo curvilíneo de la cubierta, se advierten semejanzas con las andas de La Rambla (Córdoba), trazados por Damián de Castro en 1781 y con las de la Catedral de Salamanca que labró Manuel García Crespo en 1728 según diseño de Alberto Churriguera. Ello nos hace sospechar que las andas hay que situarlas en las primeras etapas de producción del artista cerca, quizás, estilísticamente hablando, de los trabajos de su maestro el artífice Gregorio de Miranda “...en cuyo taller estuvo de aprendiz y oficial... hasta que se aprobó de maestro" 11 . Si nos atenemos a las normas

9. JJ. MARTf́N GONZÁLEZ y J. URREA: Catálogo Monumental... Monumentos civiles, pág. 36.

10. Nuestro sincero agradecimiento a Luis Luna Moreno, Director del Museo Nacional de Escultura, y al Sr. Cura Párroco de la parroquia de Salvador Santiago de Valladolid por su desinteresada ayuda y por las facilidades prestadas para localizar y fotografiar las andas.

11. Así lo afirman Félix Álvarez y Cayetano Fernández que testifican a favor del platero el diecisiete de noviembre de 1804 a petición del ensayador mayor, Manuel Lamas, según se recoge en el expediente formado con motivo de su examen de marcador. 
que dictan las Ordenanzas de 1771 sobre aprendices y oficiales, este suceso debió ocurrir poco después de 1781, ya que Bercial entraría de aprendiz entre los doce o catorce años de edad, es decir, entre 1771-73, y se examinaría diez años más tarde tras un aprendizaje de seis años y otros cuatro más como oficial $^{12}$. En cualquier caso, la prueba de maestría hay que situarla entre el doce de octubre de $1781^{13}$ y el seis de febrero de $1788^{14}$. Si, además, consideramos que, por estos años, la Hermandad de Nuestra Señora de la Valbanera había acordado hacer una nueva capilla para su titular y que en 1787 se fecha la terminación de su adorno interior, su reja y su retablo ${ }^{15}$, parece lógico suponer que las andas y la peana de la Virgen hubieron de encargarse también en estos momentos poco más o menos. En el peor de los casos, la fecha límite para su ejecución habría que fijarla antes del quince de diciembre 1801 en que el platero las menciona en su "curriculum", según antes comentamos.

No obstante, sea cual fuere, la fecha exacta de su realización, hay que admitir que se trata de una pieza bastante floja que no justifica en absoluto los encendidos elogios que Bercial pone en boca de sus contemporáneos. Por otra parte, su bajo nivel artístico es un síntoma revelador de la situación del Colegio de Plateros vallisoletano en torno a 1800 y de su progresivo declive que, en el año 1802 hizo exclamar al Subdelegado de la Junta de Comercio y Moneda en la ciudad, José Valdés, que no existía actualmente en Valladolid ningún individuo que pudiera desempeñar el cargo de marcador con acierto "por no tener conocimiento de los metales y ser tan sólo artífices de alhajas menores..."16. Esta crítica situación de la platería vallisoletana se puede explicar, al menos en parte, por la progresiva introducción de piezas salmantinas, cuyos obradores en pleno auge y difusión competían con ventaja en el mercado vallisoletano por la mejor calidad de sus productos ${ }^{17}$.

En definitiva, podemos concluir a la vista de las andas que la figura de Bercial del Valle interesa mucho más por su accidentada trayectoria personal dentro del Colegio de Plateros -recordemos a este respecto sus tentativas para alcanzar el puesto de marcador de corte- que por la calidad conseguida en el ejercicio de su profesión, pese a que tanto los cargos que desempeñó como sus relaciones personales y profesionales o su actividad lo señalen como

12. Ordenanzas de Carlos III de 1771 , título $44^{\circ}$, capítulos $6 .^{\circ}$ y $5 .^{\circ}$ recogido, entre otros, por PESCADOR DEL HOYO: Los gremios artesanos de Zamora, "Rev. Archivos, bibliotecas y museos", 1975, pág. 138 y J.M. CRUZ VALDOVINOS: Los plateros madrileños. Estudio de su organización corporativa, Madrid, 1983, págs. 168 y 170.

13. C. BRASAS: Op. cit., pág. 56 hace una relación de maestros vallisoletanos en esta fecha, cuyo número se eleva a diecisiete, y en ella no figura Bercial, posiblemente porque aún no se había examinado.

14. Ibídem. Pág. 60, nota 21, recoge el nombre del platero en relación con una obligación de la Casa de la Misericordia.

15. JJ. MARTIN GONZÁLEZ y J. URREA: Op. cit., pág. 43.

16. Informe del subdelegado de Valladolid, José Valdés, en relación con la provisión de contrastía.

17. C. BRASAS: Op. cit., págs. 319-321. 
a una de las figuras más destacadas en el campo de la platería vallisoletana en torno a 1800. En efecto, se sabe que fue alcalde y examinador en el año 1798, maestro del Colegio Mayor de Santa Cruz antes del 1801 y marcador de corte a partir de 1804. Asimismo se tienen noticias de que participó en la fundación y establecimiento de la Academia de la Purísima Concepción de Valladolid de la que se le nombró Académico de Primera Clase el veintiocho de octubre de 1779 e "individuo numerario innato" el diez de octubre de 1783, así como de su amistad con diversos miembros de dicha Academia como Pedro García González, profesor de arquitectura y director de álgebra o Diego Pérez Martínez, director de dibujo ${ }^{18}$. Se conoce también que entre sus clientes se encontraban el Capitán General de la Real Chancillería, marqués de Villasante, marqués de Ordoño y otros miembros de la nobleza local. De todo ello se deduce que, pese a las pocas obras que conocemos de su mano, no debió faltarle trabajo ${ }^{19}$. A este respecto cabría recordar que el día veintiocho de julio del año 1804 él mismo solicita a la Junta madrileña una prórroga de dos meses para efectuar su examen de marcador "...porque se halla todavía sumamente ocupado en una obra muy considerable de su arte que no puede dejarla de su mano hasta concluirla, para lo que necesita, a lo menos, dos meses..."20. Por ello, y aunque después de todo lo expuesto podamos dudar de la calidad de esta obra desconocida, es evidente que Bercial del Valle debió gozar de gran estimación en determinados círculos locales contemporáneos.

18. Muchos de estos datos, como todos aquéllos de los que no se indica su procedencia, están recogidos de la documentación del Archivo de Indias citada en la nota $n .^{\circ} 1$.

19. Vid. nota 3.

20. Esta petición está incorporada en la documentación para provisión de contrastía que recayó en el interesado. 


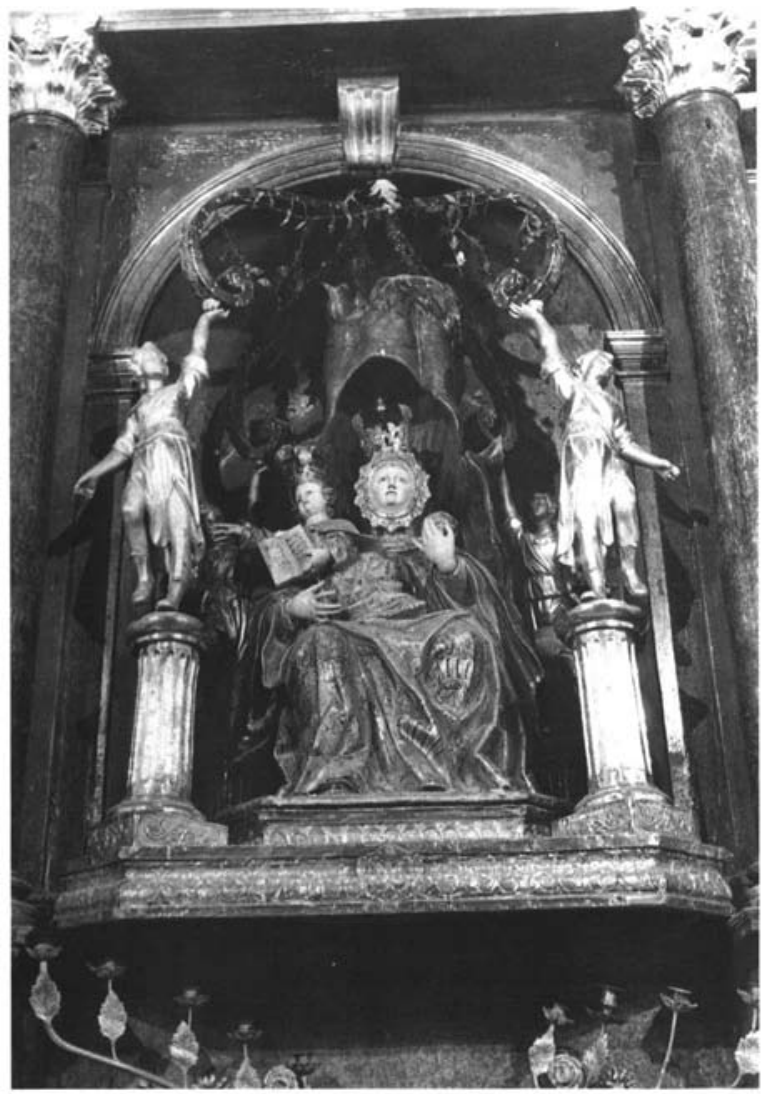

Figura 1

Andas de Ntra. Sra. de la Valbanera. Parroquia del Salvador de Valladolid. 


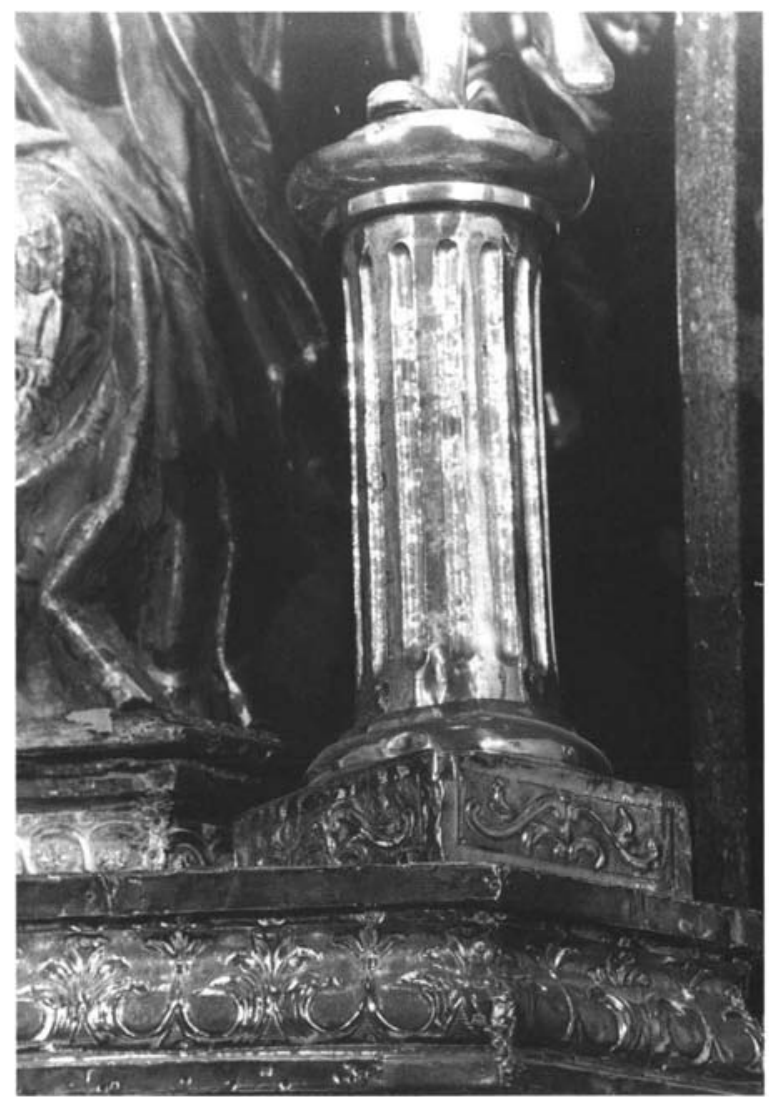

Figura 2

Detalle de la figura anterior. Soportes. 


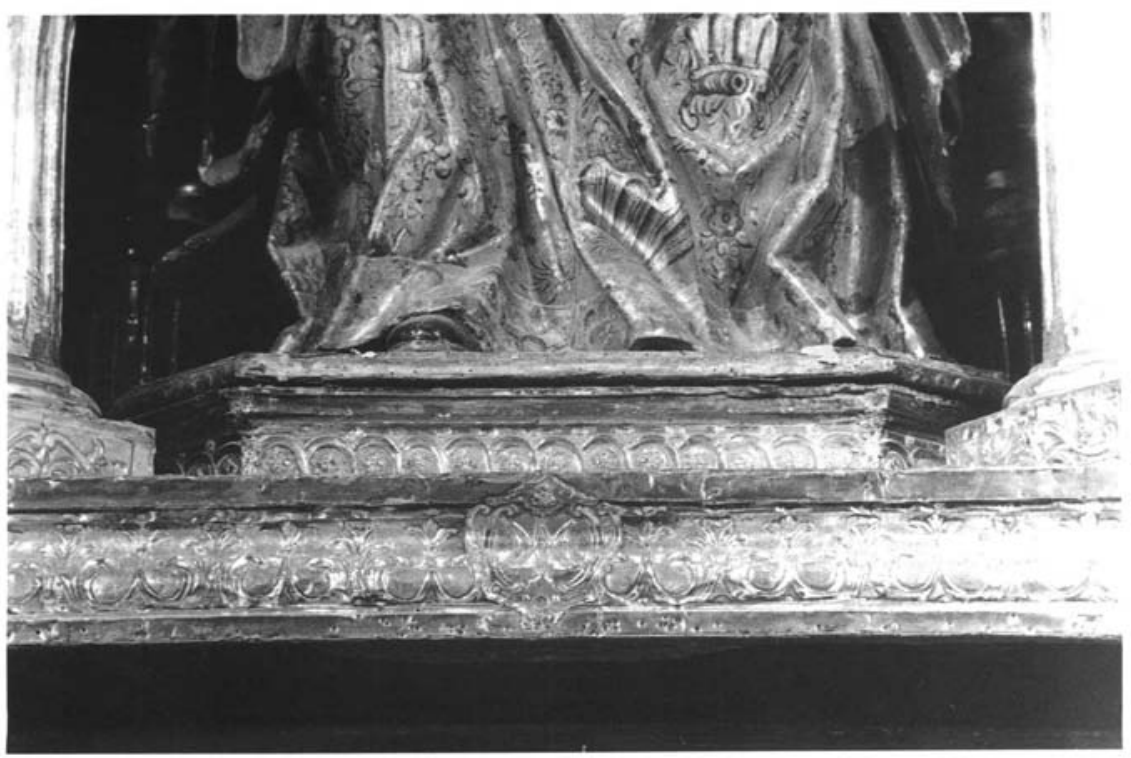

